\title{
Commentary
}

\section{CAM for Pediatric Pain: What is State-of-the-Research?}

\author{
Jennie C. I. Tsao \\ A Commentary for eCAM on CAM and the Phenomenology of Pain, by Alex Hankey
}

\begin{abstract}
Previously, we reviewed the evidence for the efficacy of CAM approaches for pediatric pain (volume 2; issue 2; 2005) using criteria developed by the American Psychological Association Division 12 Task Force. Our review focused on CAM modalities that had been tested with at least one controlled trial or multiple baseline study. In addition, only those trials in which children comprised the study sample were included. Thus, several CAM modalities were not included in our review. Key ethical and other reasons for the limited literature on CAM for pediatric pain as well as directions for future studies are discussed.
\end{abstract}

The commentary by Alex Hankey on our article, 'Complementary and Alternative Medicine Approaches for Pediatric Pain' (1), raised some valuable points regarding the practice of CAM interventions for chronic and acute pain. Whereas it is certainly true that CAM consists of many more modalities than those reviewed in our article, the intent of the review was to focus on those modalities that had at least one controlled trial or at least one multiple baseline study in the peer-reviewed literature (see page 150). Thus, our review did not include several of the modalities discussed in Dr Hankey's Commentary, including hands-on or distance healing, meditation, Traditional Chinese Medicine, and Ayurveda. Our review was not intended to either implicitly or explicitly exclude these modalities without relevant published literature from the list of potentially safe and efficacious CAM treatments for pain. Instead, we had hoped to stimulate further research into those approaches that had not been the subject of controlled or multiple baseline trials.

Another important consideration is that our review focused on CAM interventions which have been studied in children. The published literature on the application of CAM for pain in pediatric populations is fairly limited and lags behind the work that has been conducted on adult populations. Certainly, there are several good reasons for the relative paucity of CAM treatment studies in children. For example, solid evidence of

For reprints and all correspondence: Jennie C. I. Tsao, Pediatric Pain Program, Department of Pediatrics, David Geffen School of Medicine at UCLA, 10940 Wilshire Boulevard, Suite 1450, Los Angeles, California 90024, USA.

Tel: +1 310824 7667; Fax: +1 310824 0012; E-mail: jtsao@mednet.ucla.edu acceptably low probability of side effects and adverse events is required before clinical researchers would be willing to test a CAM intervention in pediatric samples, and for parents to consent to their child taking part in such trials. There is also the ethical consideration that only those modalities with a reasonable amount of evidence supporting analgesic effects in adults should be studied in children. This concern limits the range of CAM interventions that have been researched in younger populations.

In addition, as we pointed out in our review, certain modalities may have an 'image problem' when it comes to convincing children and their parents to participate in treatment and/or research trials. This potential problem is probably best illustrated by considering the case of acupuncture. The conventional view is that children have an aversion to needles, and this conventional wisdom may complicate referrals to acupuncturists (2), and by extension, participation in clinical trials. Despite a few studies showing that acupuncture is acceptable to chronic pediatric pain patients and their families $(2,3)$, it is possible that researchers have not been able to recruit sufficient numbers of participants to conduct acupuncture trials, or that such trials are never initiated due to concerns regarding patient recruitment and retention. We recently found that both children and their parents presenting for treatment at a tertiary pediatric pain clinic had low expectations for the benefits of a number of CAM approaches, including hypnosis, massage, acupuncture, yoga and relaxation (4). Such low expectations for CAM may adversely impact not only possible participation in treatment studies but also actual clinical outcomes. It is hoped that educational and other 'PR' efforts

(C) The Author (2006). Published by Oxford University Press. All rights reserved.

The online version of this article has been published under an open access model. Users are entitled to use, reproduce, disseminate, or display the open access version of this article for non-commercial purposes provided that: the original authorship is properly and fully attributed; the Journal and Oxford University Press are attributed as the original place of publication with the correct citation details given; if an article is subsequently reproduced or disseminated not in its entirety but only in part or as a derivative work this must be clearly indicated. For commercial re-use, please contact journals.permissions@oxfordjournals.org 
may improve the acceptability of CAM interventions for pain in pediatric populations, leading to more published research and potentially, improved treatment outcomes.

Finally, the intent of the review was to compare the existing published data on the efficacy of CAM for pediatric pain to a single standard: American Psychological Association Division 12 Task Force on Promotion and Dissemination of Psychological Procedures (5). Although these criteria are well-established and widely recognized, they are not the only standard by which studies of CAM for pain relief may be judged. Recently, it has been recognized that sole reliance on quantitative data (e.g. numeric rating scales) to assess clinical outcomes involving complex interventions such as CAM modalities, may obscure important aspects of treatment response. Thus, there is a growing awareness of the value of qualitative research methods which allow the systematic examination of key contextual factors within which clinical outcomes occur (6). Future work may therefore combine both qualitative and quantitative methods to enhance our understanding of the process of healing as well as the phenomenology of pain itself.

\section{Acknowledgements}

Support for this work was provided in part by 1R01MH063779, awarded by the National Institute of Mental Health (PI: Margaret C. Jacob).

\section{References}

1. Tsao JCI, Zeltzer LK. Complementary and alternative medicine approaches for pediatric pain: a review of the state-of-the-science. Evid Based Complement Alternat Med 2005;2:149-59.

2. Kemper KJ, Sarah R, Silver-Highfield E, Xiarhos E, Barnes L, Berde C. On pins and needles? Pediatric pain patients' experience with acupuncture. Pediatrics 2000;105:941-7.

3. Zeltzer LK, Tsao JCI, Stelling C, Powers M, Levy S, Waterhouse M. A Phase I study on the feasibility of an acupuncture/hypnotherapy intervention for chronic pediatric pain. J Pain Symptom Manage 2002;24:437-46.

4. Tsao JCI, Meldrum M, Bursch B, Jacob MC, Kim SC, Zeltzer LK. Treatment expectations for CAM interventions in pediatric chronic pain patients and their parents. Evid Based Complement Alternat Med 2005;2:521-7.

5. Task Force on Promotion and Dissemination of Psychological Procedures. Training in and dissemination of empirically validated psychological treatments: report and recommendations. Clin Psychol 1995;48:3-23.

6. Crawford MJ, Weaver T, Rutter D, Sensky T, Tyrer P. Evaluating new treatments in psychiatry: The potential value of combining qualitative and quantitative research methods. Int Rev Psychiatry 2002;14:6-11. 


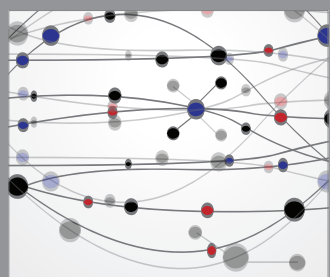

The Scientific World Journal
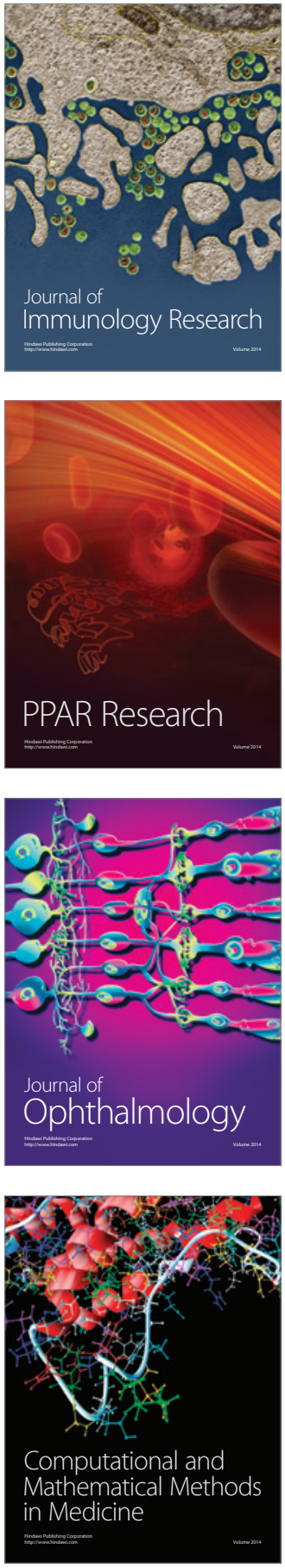

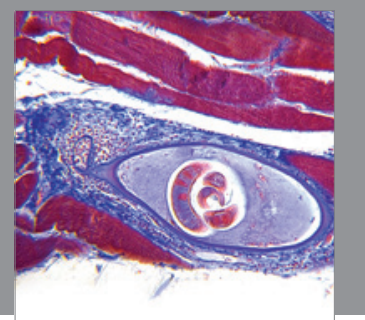

Gastroenterology

Research and Practice
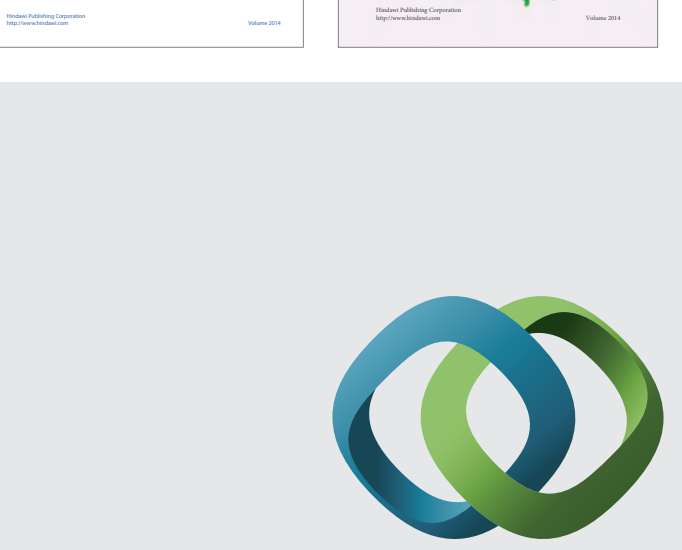

\section{Hindawi}

Submit your manuscripts at

http://www.hindawi.com
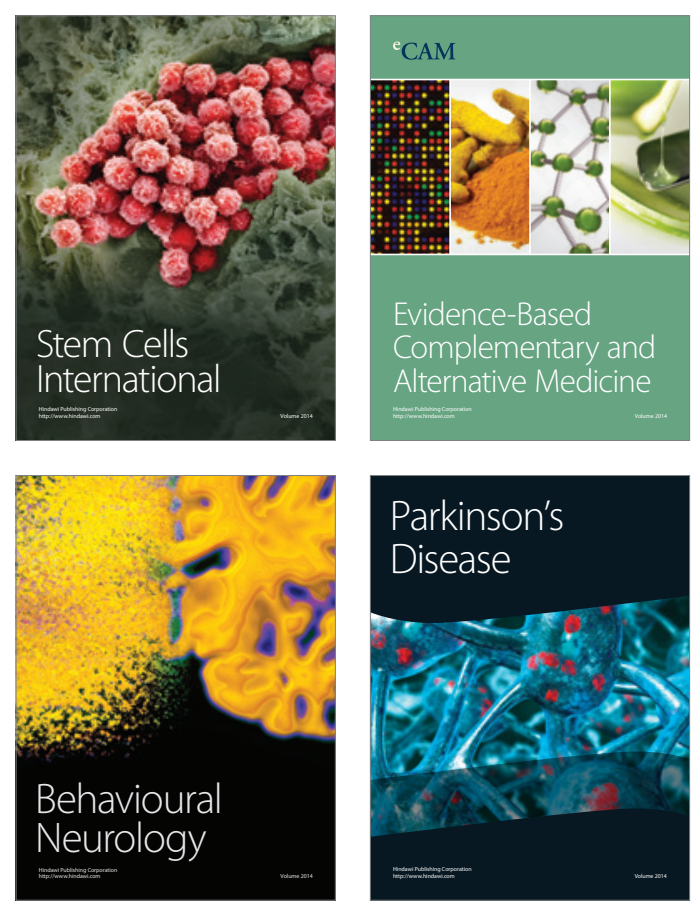

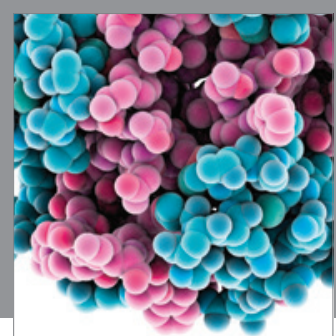

Journal of
Diabetes Research

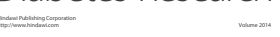

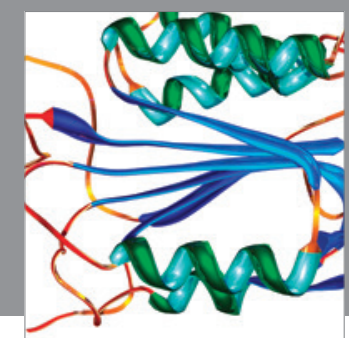

Disease Markers
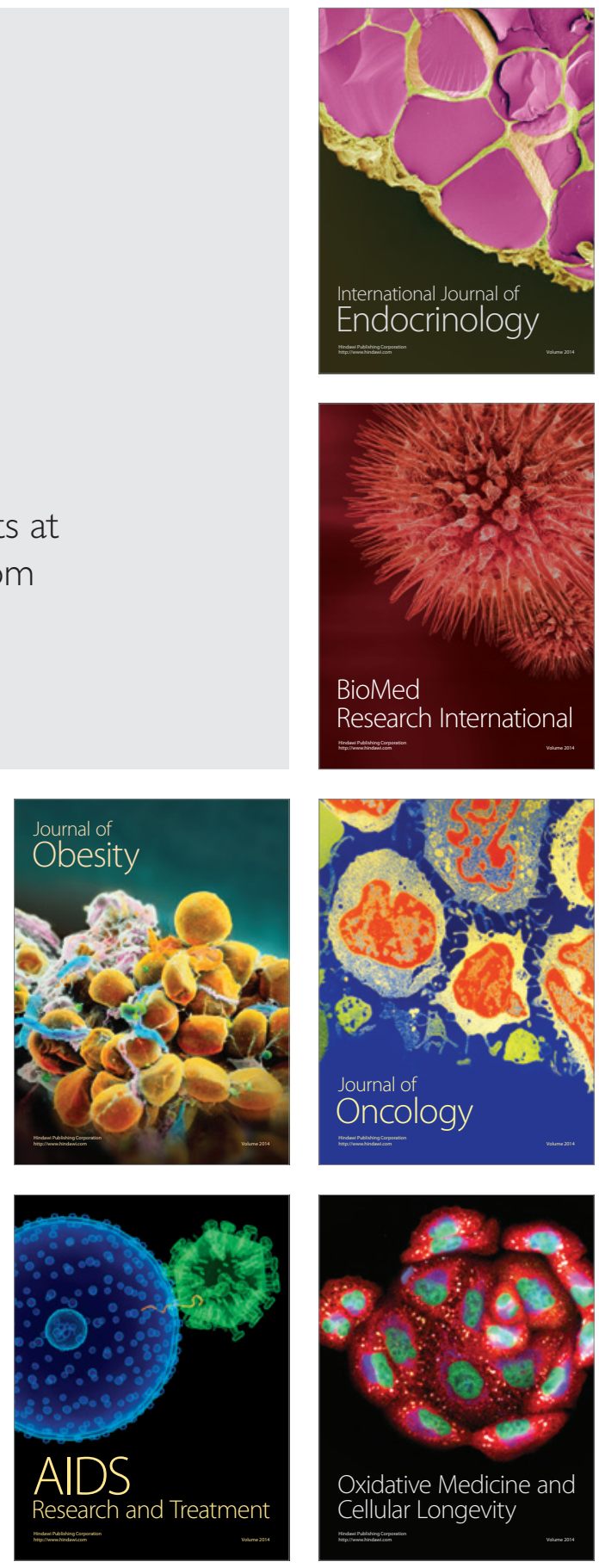